\title{
The effect of carbon dioxide therapy on composite graft survival ${ }^{1}$
}

\author{
Eliana Ferreira Ribeiro Durãesı, Leonardo de Castro Durães ${ }^{\mathrm{II}}$, Fabiana Pirani Carneiro"II, Ruy de Souza Lino Júnior ${ }^{\mathrm{IV}}$, João \\ Batista de Sousav
}

\begin{abstract}
IFellow Master degree, Postgraduate Program in Medical Sciences, Medical School, University of Brasilia (UnB), Brasilia- DF, Brazil. Intellectual, design and scientific content of the study, technical procedures, acquisition and interpretation of data, manuscript writing, critical revision.

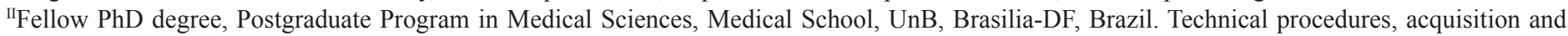
interpretation of data, statistical analysis, critical revision.

IIIPhD, Associate Professor, Pathology Department, Medical School, UnB, Brasilia-DF, Brazil. Pathological examinations, critical revision.

${ }^{\mathrm{IV}} \mathrm{PhD}$, Associate Professor, Pathology Department, Institute of Tropical Pathology and Public Health, Federal University of Goias (UFG), Goiania-GO, Brazil. Histomorphometry of collagen analysis, critical revision.

vPhD, Associate Professor, Surgery Department, Medical School, UnB, Brasilia-DF, Brazil. Intellectual, design and scientific content of the study, technical procedures, interpretation of data, manuscript writing, critical revision.
\end{abstract}

\begin{abstract}
PURPOSE: To investigate the effect of carboxytherapy in auricular composite grafts in rabbits.

METHODS: An experimental study was conducted using 20 rabbits randomly assigned to a treatment group of carboxytherapy or a control group of saline solution. In each ear, a circular graft with $1.5 \mathrm{~cm}$ or $2 \mathrm{~cm}$ of diameter was amputated and reattached. Animals underwent carbon dioxide or saline injection four times during the experiment. We analyzed clinical evolution of the animals, grafts survival, histopathology features and histomorphometry of collagen.

RESULTS: The treated group had a significantly lower weight gain $(p=0.038)$. Histopathology was not significantly different between groups. There was an increase in amount of collagen in $2 \mathrm{~cm}$ grafts submitted to carbon dioxide therapy $(p=0.003)$. Carboxytherapy didn't influence graft survival rate for $1.5 \mathrm{~cm}$ grafts or $2 \mathrm{~cm}$ grafts ( $p=0.567$ and $p=0.777$, respectively).

CONCLUSIONS: Carbon dioxide therapy increased the amount of collagen in $2 \mathrm{~cm}$ grafts. $\mathrm{CO}_{2}$ was not significantly different from saline infusion on composite grafts survival, but this study suggests that there is a mechanical effect caused by distension which favored graft survival.
\end{abstract}

Key words: Wound Healing. Graft Survival. Carbon Dioxide. Rabbits. 


\section{Introduction}

Composite grafts are defined as the transfer of tissues histologically differents but interconnected anatomically. The most common type is the auricular composite graft which is a valuable option to reconstruct the 3-dimensional structure of the nasal alae. Auricular composite grafts have been used for over 100 years. Traditionally, the maximum diameter of a full-thickness graft that can be used successfully ranges from 0.75 to $1.5 \mathrm{~cm}^{1}$.

Carbon dioxide $\left(\mathrm{CO}_{2}\right)$ therapy is the use of $\mathrm{CO}_{2}$ subcutaneously. The effect of such administration is effective not only in improving circulation and perfusion parameters of injection site but also inducing an increase in tissue oxygen partial pressure $^{2-10}$. This may be due to a hypercapnia-induced capillary blood flow and an increase in local oxygen $\left(\mathrm{O}_{2}\right)$ availability caused by its release from haemoglobin related to reduction in $\mathrm{pH}$ (Bohr effect) $)^{2-7} \cdot \mathrm{CO}_{2}$ has been used for centuries with carbonated water baths in natural pools. Therapeutic indications of $\mathrm{CO}_{2}$ therapy include vascular, cardiac, metabolic and rheumatic diseases, cellulite, chronic wounds, localized adiposities, migraine headaches. It is used, as well, in radiology to guided catheters placement and in laparoscopic surgeries for visualization of the surgical field ${ }^{3-6,8-17} \cdot \mathrm{CO}_{2}$ therapy is safe, with low cost, no toxicity or side effects ${ }^{3-5,12,17}$.

Histological changes after the carbon dioxide therapy include: fracturing of the adipose tissue with release of triglycerides, thickening of the dermis, increase and realingment of the collagenous fibers, increase in the number and diameter of capillaries, increase of macrophages and fibroblasts ${ }^{2-6,18}$.

The need for a treatment strategy to increase composite graft survival, the possibility of improving microcirculation and oxygenation with the use of the $\mathrm{CO}_{2}$ therapy that would make survival of larger grafts possible, and the lack of scientific publications attesting the method led us to this study.

The objective was to evaluate the effect of $\mathrm{CO}_{2}$ therapy in auricular composite grafts in rabbits.

\section{Methods}

Approval from the Ethics Committee on Animal Use from the Institute of Biological Sciences, University of Brasilia, Brazil.

Twenty New Zealand male rabbits underwent a minimum of five days acclimation period. Each animal was randomly assigned to either treatment group with $\mathrm{CO}_{2}$ therapy or control group with saline solution that was done two days prior to surgery, at the day of the surgery, on post operative days five and $12 . \mathrm{CO}_{2}$ therapy was done with $50 \mathrm{ml}$ of the gas administered with a infusion rate of 80 $\mathrm{ml} / \mathrm{min}$, with eight punctures circling radially the graft, done at both surfaces of each ear. Saline solution injection was made with $1.5 \mathrm{ml}$, similarly. At first session of carboxitherapy/saline solution, administration was held on entire ears surface. After surgery, only grafts sorrounding area was injected. The buldging, caused by injection of eather gas or saline, could be macroscopically seen, which garantees the injection of the whole area.

Animals were anesthetized using a combination of ketamine hydrochloride, $30 \mathrm{mg} / \mathrm{kg}$ and xylasine hydrochloride, $10 \mathrm{mg} / \mathrm{kg}$ administered by intramuscular injection and a subcutaneous injection of $1.5 \mathrm{ml}$ of $1 \%$ xylocaine circulating the base of each ear. The ears were shaved and prepared with povidone-iodine solution. A $1.5 \mathrm{~cm}$ punch was used to harvest the full-thickness composite chondrocutaneous graft in one side and a $2 \mathrm{~cm}$ punch was used in the other side. Grafts were rotaded $90^{\circ}$ within each site and sutured into place on both ventral and dorsal surfaces with 5-0 Nylon running sutures (Figure 1).

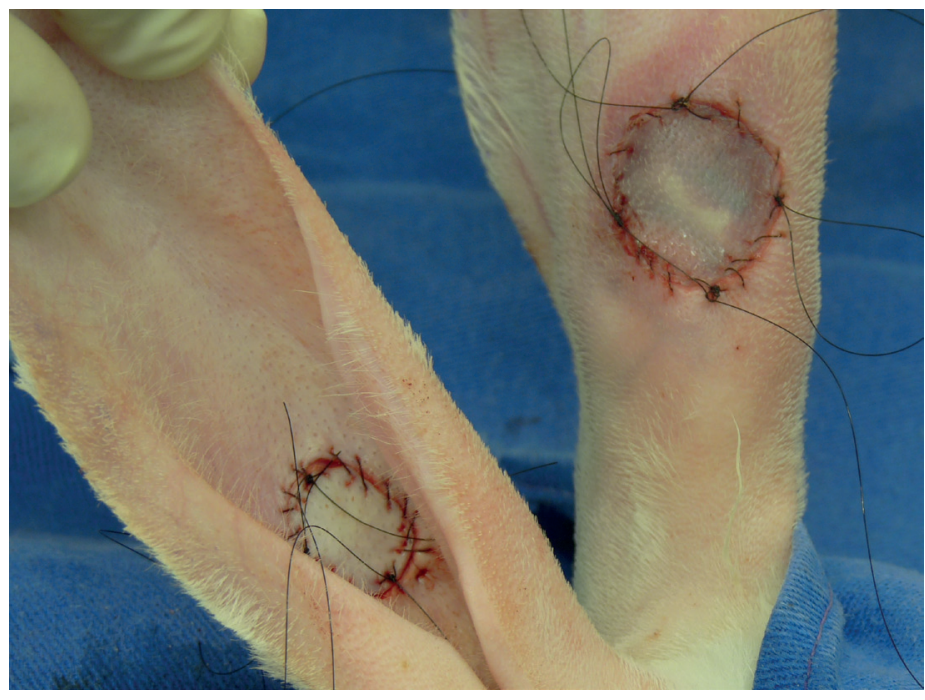

FIGURE 1 - Grafts on its final position, prepared for tie-over dressings.

A tie-over dressing with Neomicin and Bacitracin was used along with a colar to prevent manipulation of grafts by the animals (Figure 2). 


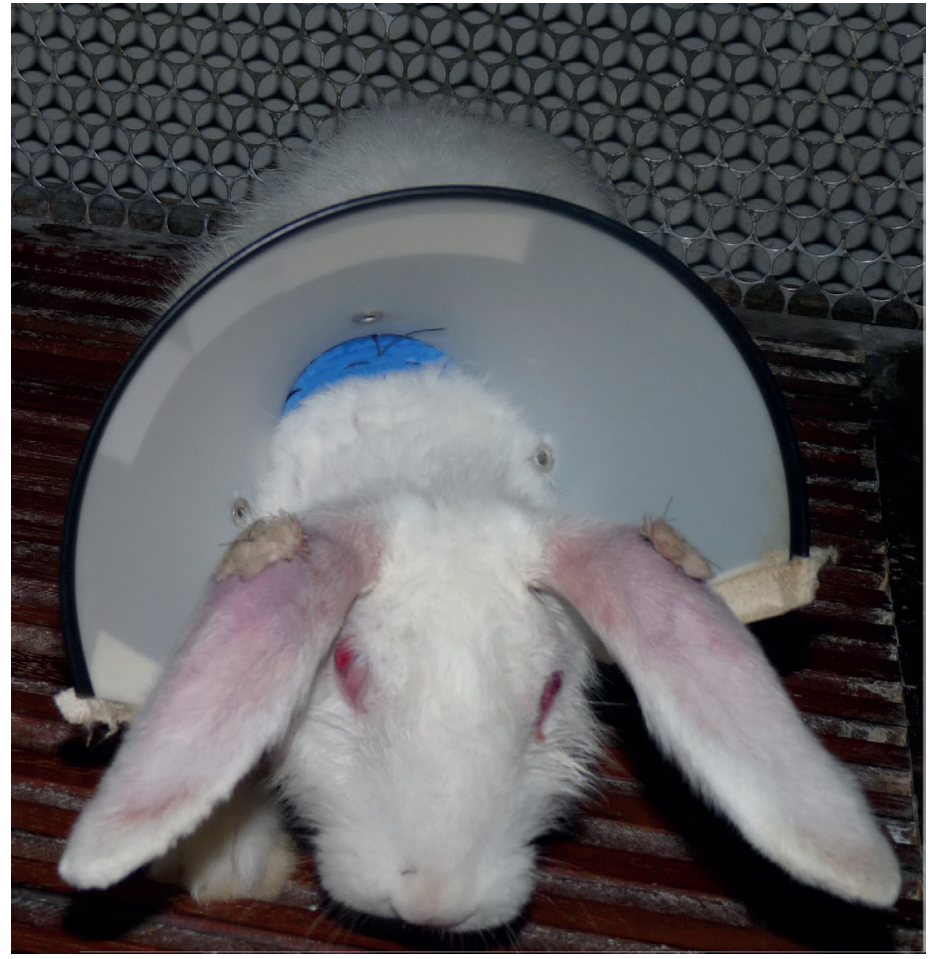

FIGURE 2 - Rabbit with tie-over dressing and colar.

All surgical procedures were performed by the same surgeon. Animals were evaluated daily and killed on postoperative day 21. Digital pictures were obtained at a set distance, using a metric ruler as a background reference and were analyzed using Image J $\mathrm{NIH}^{\square}$ software to calculate percentage of graft survival. Grafted area and $0.5 \mathrm{~cm}$ of surrounding tissue were ressected and prepared for histological examination and collagen histomorphometry. Slides containing sample of grafted area, stained with hematoxylin and eosin, were analyzed for presence of neovascularization, collagen, fibroblasts, mononuclear cells, epithelial hyperplasia, viable hair follicles, necrosis of cartilage and skin ulceration. The histomorphometry was done with slides steined with Picro-sirius and use of Image $\mathrm{J} \mathrm{NIH}^{\circledR}$ software to calculate the amount of collagen in each slide. We analyzed separately $1.5 \mathrm{~cm}$ grafts and $2 \mathrm{~cm}$ grafts. The amount of collagen was measured in three areas: peri-graft, called here as edge, transition area and grafted area. For statistical analysis we use Special Package for Social Sciences SPSS 20.0 and a $\mathrm{p}<0.05$ was considered significant.

\section{Results}

Two animals, from the treated group, died during anestesia for carboxytherapy on postoperative days five and 12 , respectively.

All animals gained weight during experimental period.
Comparing weight gain among animals from treated group (average gain $318.75 \mathrm{~g} \pm 143.77 \mathrm{~g}$ ) and control group (mean gain $530 \mathrm{~g} \pm 245.18 \mathrm{~g}$ ), treated group won less weight than animals in control group and this difference was statistically significant ( $\mathrm{p}=$ 0.038) (Figure 3).

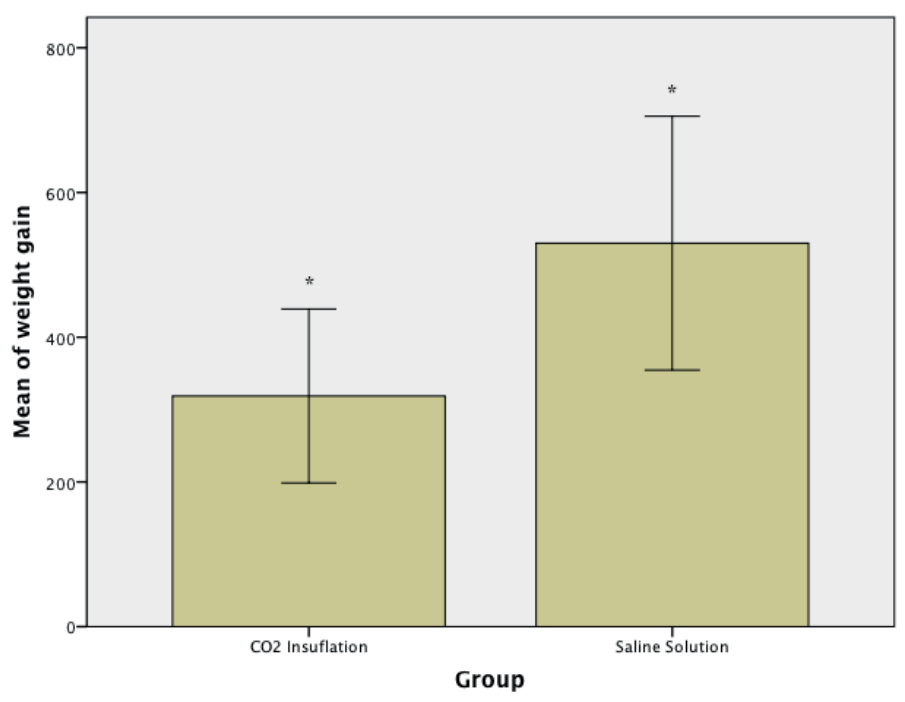

FIGURE 3 - Mean weight gain of the two groups. Weight gain in treated group was lower than in control group, weight in grams.

In treated group, $1.5 \mathrm{~cm}$ grafts had a survival rate measured from the external surface of the ear of $77.16 \%$ to $100 \%$ (mean $90.20 \%$ ), while control group varied from $77.17 \%$ to $100 \%$ (mean 92.70\%). Comparing the groups, there was no significant difference $(p=0.567)$ (Figure 4$)$.

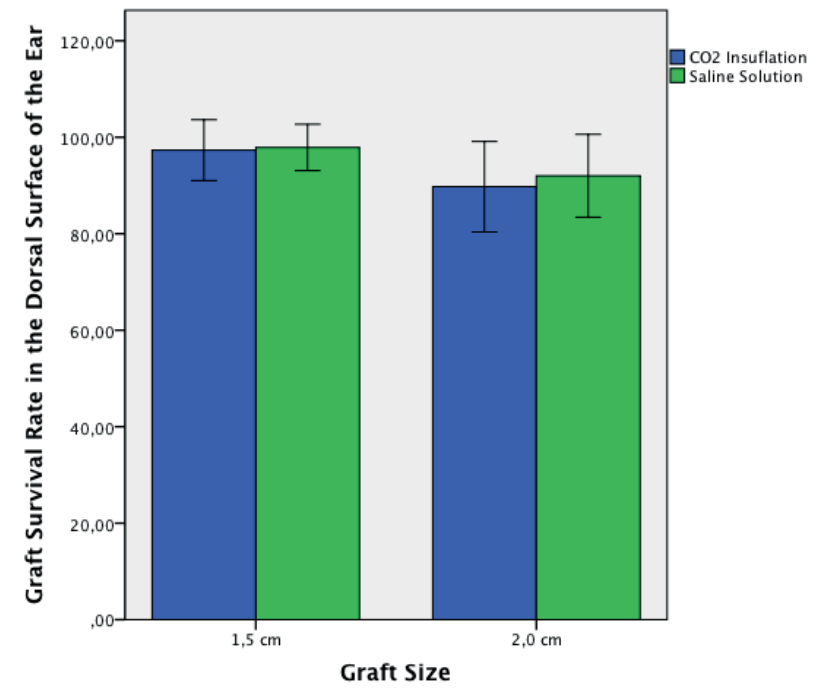

FIGURE 4 - Survival rate calculated from dorsal surface of the ears: comparison between groups and graft size.

In $2 \mathrm{~cm}$ grafts, treated group showed a percentage of graft survival measured from external surface of the ear of $61.46 \%$ 
to $98.14 \%$ (mean $80.79 \%$ ), while the rate in control group ranged from $68.76 \%$ to $100 \%$ (mean $82.45 \%$ ). When comparing both groups, no significant difference in percentage of graft survival was found $(p=0.777)$ (Figure 4).

The graft size influence the percentage of survival. The $1.5 \mathrm{~cm}$ grafts had a higher survival rate $(\mathrm{p}=0.008)$.

There was no significant difference among groups in histopathological features, analyzing grafted area.

The amount of collagen on edge was higher than in transition area $(\mathrm{p}=0.007)$, and also higher when compared with grafted area $(p<0.001)$. Comparing transition to grafted area the amount of collagen was higher again $(\mathrm{p}<0.001)$ (Figure 5).

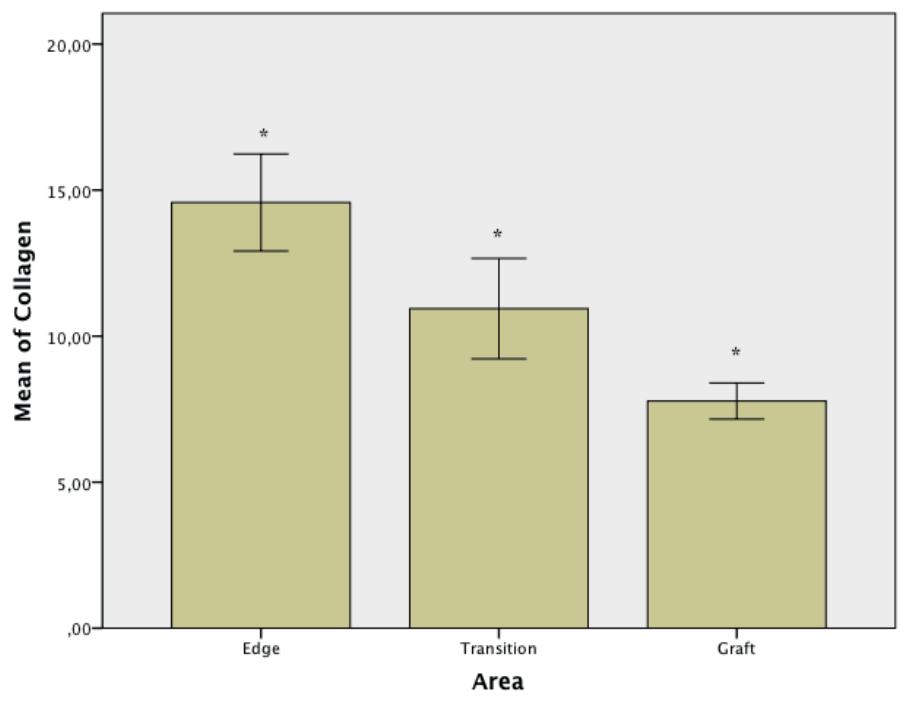

FIGURE 5 - Comparison of amount of collagen according to area. The amount of collagen was higher in edge compared to transition area $(\mathrm{p}=0.007)$ and to graft area $(\mathrm{p}<0.001)$. Collagen was higher in transition area than in graft area $(\mathrm{p}<0.001)$.

Among $1.5 \mathrm{~cm}$ grafts, use of saline solution or carboxitherapy did not alter the amount of collagen $(p=0.329)$. However, in $2 \mathrm{~cm}$ grafts, use of $\mathrm{CO}_{2}$ therapy increased the amount of collagen founded $(\mathrm{p}=0.003)$ (Figure 6).

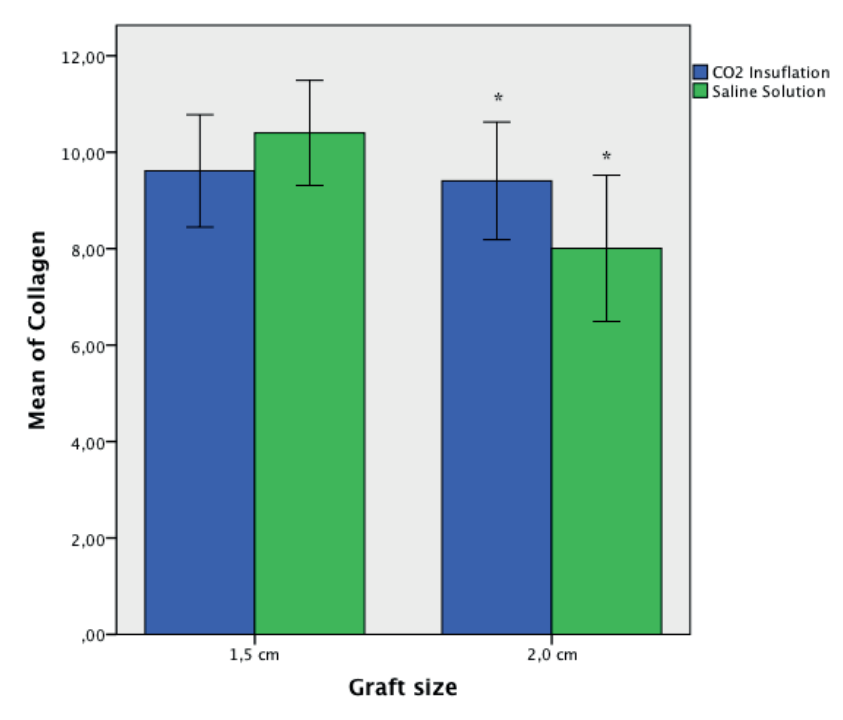

FIGURE 6 - Comparison of the amount of collagen in 1.5 and $2 \mathrm{~cm}$ grafts of treated and control group. In $1.5 \mathrm{~cm}$ grafts no significant difference was found $(\mathrm{p}=0.329)$, the $2 \mathrm{~cm}$ grafts of treated group had a increase in the amount of collagen $(\mathrm{p}=0.003)$.

\section{Discussion}

Considering that animals were still in growth phase, it was expected, as occurred, that all animals gained weight during the experiment. The influence of carbon dioxide therapy in weight gain was not object of this study, but this finding is intriguing and raise questions for future experiments. Lee, in 2010, noted that when using carboxitherapy for treatment of cellulite, female patients had a significant weight loss, which was not observed in male patients ${ }^{13}$.

Although we did not observe a significant difference in percentage of graft survival in the treated group, we observed that percentage of graft survival was quite high in both groups compared with reports from other studies using the same animal model. In the present study, $1.5 \mathrm{~cm}$ grafts of treated group had a mean survival rate of $90.2 \%$ and control group $92.7 \% ; 2 \mathrm{~cm}$ grafts of treated group presented a mean survival rate of $80.79 \%$ while control group had a mean graft survival rate of $82.45 \%$.

Li et al. ${ }^{14}$, in a study that evaluated the use of hyperbaric oxygen therapy in auricular composite grafts in rabbits, had an average of $85.8 \%$ of graft survival in the group undergoing hyperbaric oxygen therapy and $51.31 \%$ of graft survival in control group, using circular grafts with the same location of this study.

Lewis et al. ${ }^{1}$, in another study that evaluated the use of hyperbaric oxygen therapy in auricular composite grafts in rabbits, obtained a percentage of graft survival of $80.67 \%$ on average in treated group, while the control group showed a percentage of $26.33 \%$ on average. This study used semi-circular grafts at the free 
edge of the ear, which may have hindered graft survival.

Relying on a possible mesotherapic effect in both groups, it is possible that multiple punctures and distension caused by both saline solution and $\mathrm{CO} 2$ therapy have positively influenced the grafts survival, what would explain the high percentage of graft survival in the whole study ${ }^{15}$.

Physical effects of distension caused by gas insuflations were observed in a study that assessed the effects caused by $\mathrm{CO}_{2}$ therapy in the treatment of localized adiposities. This study had five groups: sham group, acute effect of $\mathrm{CO}_{2}$ group, acute effect of breathable air group, chronic effect of $\mathrm{CO}_{2}$ group, and chronic effect of breathable air group. They observed a decrease in volume of adipocytes, increased collagen, fibroblasts activity and vascularization both in $\mathrm{CO}_{2}$ therapy group as in breathable air group when compared to sham group with no insufflation. With decrease in adipocyte volume defined as an achievement, $\mathrm{CO}_{2}$ therapy was more successful than air injection, but both groups had a positive effect compared to sham group ${ }^{3}$.

If the mechanical effect exists, it can also be caused by infiltration of saline and may have influenced the present study.

Carbon dioxide therapy increased the amount of collagen in $2 \mathrm{~cm}$ grafts when compared to saline, but not in $1.5 \mathrm{~cm}$ grafts. The increase in amount of collagen agree with other studies such as one held by Ferreira et al. ${ }^{10}$ that observed an increase in collagen turnover in rats submitted to carboxitherapy compared to saline solution, and a compaction of collagen fibers.

\section{Conclusions}

Carbon dioxide therapy increased the amount of collagen in $2 \mathrm{~cm}$ grafts when compared to saline solution. $\mathrm{CO}_{2}$ therapy was not significantly different from saline infusion on composite grafts survival, but this study suggests that there is a mechanical effect caused by distension which favored graft survival.

\section{References}

1. Lewis D, Goldztein H, Deschler D. Use of hyperbaric oxygen to enhance auricular composite graft survival in the rabbit model. Arch Facial Plast Surg. 2006;8(5): 310-3.

2. Abramo AC, Teixeira TT. Carboinsuflação em úlceras crônicas de membros inferiores. Rev Bras Cir Plást. 2011;26(2):205-10.

3. Balik O, Yilmaz M, Bagriyanik A. Does carbon dioxide therapy really diminish localized adiposities? experimental study with rats. Aesthetic Plast Surg. 2011;35(4):470-4.

4. Brandi C, Grimaldi L, Nisi G, Brafa A, Campa A, Calabrò M, Campana M, D'Aniello C. The role of carbon dioxide therapy in the treatment of chronic wounds. In Vivo. 2010;24(2):223-6.

5. Brandi C, D'Aniello C, Grimaldi L, Caiazzo E, Stanghellini E. Carbon dioxide therapy: effects on skin irregularity and its use as a complement to lipossuction. Aesthetic Plast Surg. 2004;28(4):2225 .

6. Brandi C, D’Aniello C, Grimaldi L, Bosi B, Dei I, Lattarulo P, Alessandrini C. Carbon dioxide therapy in the treatment of localized adiposities: clinical study and histopathological correlations. Aesthetic Plast Surg. 2001;25(3):170-4.

7. Jensen FB. Red blood cell $\mathrm{pH}$, the Bohr effect, and other oxygenation-linked phenomena in blood $\mathrm{O}_{2}$ and $\mathrm{CO}_{2}$ transport. Acta Physiol Scand. 2004;182(3):215-27.

8. Brockow T, Hausner T, Dillner A, Resch KL. Clinical evidence of subcutaneous $\mathrm{CO}_{2}$ insufflations: a systematic review. J Altern Complement Med. 2000;6(5):391-403.

9. Fabry R, Monnet P, Schmidt J, Lusson JR, Carpentier PH, Baguet JC, Dubray C. Clinical and microcirculatory effects of transcutaneous $\mathrm{CO}_{2}$ therapy in intermittent claudication. Randomized double-blind clinical trial with a parallel design. Vasa. 2009;38(3):213-24.

10. Ferreira JC, Haddad A, Tavares SA. Increase in collagen turnover induced by intradermal injection of carbon dioxide in rats. J Drugs Dermatol. 2008;7(3):201-6.

11. Hartmann BR, Bassenge E, Pittler M. Effect of carbon dioxideenriched water and fresh water on the cutaneous microcirculation and oxygen tension in the skin of the foot. Angiology.1997;48(4):337-43.

12. Ito T, Moore JI, Koss MC. Topical application of $\mathrm{Co}_{2}$ increases skin blood flow. J Invest Dermatol. 1989;93(2):259-62.

13. Lee GSK. Carbon dioxide therapy in the treatment of cellulite: an audit of clinical practice. Aesthetic Plast Surg. 2010;34(2):239-43.

14. Li EN, Menon NG, Rodrigues ED, Norkunas M, Rosenthal RE, Goldberg NH, Silverman RP. The effect of hyperbaric oxygen therapy on composite graft survival. Ann Plastic Surg. 2004;53(2):141-5.

15. Mammucari M, Gatti A, Maggiori S, Bartoletti CA, Sabato AF. Mesotherapy, defition, rationale and clinical role: a consensus report from the Italian Society of Mesotherapy. Eur Rev Med Pharmacol Sci. 2011;15(6):682-94.

16. Nach R, Zandifar H, Gupta R, Hamilton JS. Subcutaneous carboxytherapy injection for aesthetic improvement of scars. Ear Nose Throat J. 2010;89(20):64-6.

17. Piazzolla LP, Louzada LL, Scoralick FM, Martins ME, de Sousa JB. Preliminary experience with carbon dioxide therapy in the treatment of pressure ulcers in a bedridden elderly patient. J Am Geriatr Soc. 2012;60(2):378-9.

18. Sönmez A, Yaman M, Yalçin O, Ersoy B, Serin M, Sav A. Carbon dioxide therapy increases capillary formation on random pedicled skin flaps in the rat. J Plast Reconstr Aesthet Surg. 2009;62(7):e2367.

\section{Correspondence:}

João Batista de Sousa

Universidade de Brasília

Campus Universitário Darcy Ribeiro-Faculdade de Medicina

Laboratório de Cirurgia Experimental

70910-900 Brasília - DF Brasil

Tel.: (55 61)9984-2845

sousajb@unb.br

Received: April 18, 2013

Review: June 20, 2013

Accepted: July 22, 2013

Conflict of interest: none

Financial source: Coordination of Improvement for Higher Academic Staff (CAPES)

${ }^{1}$ Research performed at Experimental Surgery Laboratory, School of Medicine, University of Brasilia (UnB), Brazil. 